\title{
Contact Laser Lithotripsy Using Strongly Heated Distal Tip of Optic Fiber
}

DOI: $10.17691 / \mathrm{stm} 2017.9 .4 .17$

Received June 28, 2017

O.S. Streltsova, MD, DSc, Professor, E.V. Shakhov Urology Department";

E.V. Grebenkin, Resident, E.V. Shakhov Urology Department';

D.P. Pochtin, Urologist;

V.I. Bredikhin, DSc, Leading Researcher";

V.A. Kamensky, DSc, Leading Researcher ${ }^{3}$

${ }^{1}$ Nizhny Novgorod State Medical Academy, 10/1 Minin and Pozharsky Square, Nizhny Novgorod, 603005, Russian Federation;

${ }^{2}$ N.A. Semashko Nizhny Novgorod Regional Hospital, 190 Rodionova St., Nizhny Novgorod, 603126,

Russian Federation;

${ }^{3}$ Institute of Applied Physics, Russian Academy of Sciences, 46 Ulyanova St., Nizhny Novgorod, 603155,

Russian Federation

The aim of the study was to evaluate the developed technique of contact lithotripsy using a strongly heated distal tip of a fiber providing controlled fragmentation of urinary stones.

Materials and Methods. Postoperative kidney stones were used as research objects. For renal calculi fragmentation we applied a standard $0.97 \mu \mathrm{m}$ diode laser with a continuous wave laser regime, laser power $15 \mathrm{~W}$. As a strongly absorbing coating (SAC), we used a solution of graphite carbon microparticles in silicone varnish. SAC was localized at the distal end of the light guide of multimode quartz fiber, $d=550 \mu \mathrm{m}$. The contact zone of the light guide with a stone (heated to $2000^{\circ} \mathrm{K}$ ) was smeared with a $\mathrm{CO}_{2}$ gas stream, which made it possible to optimize the high-temperature oxidation of graphite in the destruction of stones. Laser fragmentation was performed ex vivo in physiological saline and in liquid-free conditions by means of direct calculus contact.

Results. Large calculus fragmentation was achieved through the carbonization with mechanical destruction of the surface by high temperature of an optical fiber tip. Calculus fragmentation time depended on stone density, cross-sectional dimension, and was from 10 to $80 \mathrm{~s}$. Maximum cross-sectional dimension of calculi was from 6 to $21 \mathrm{~mm}$, X-ray calculus density being 158-1,587 HU. Calculi with X-ray density of over 1,400 HU were unaffected by fragmentation in liquid, however, fragmentation in the atmospheric air proceeded successfully.

Conclusion. The use of SAC of the laser fiber tip enables to develop new calculus fragmentation mechanism and provide the break of a stone along the marked line. The technique excludes small stone fragmentation, therefore enables to prevent intra-operative microbial dissemination of renal tissue from biofilms of potentially infected calculi. New opportunities enable to use various laser types as a lithotripter, and significantly simplify and cheapen the technology of their manufacture.

Key words: laser lithotripsy; urolithiasis; infected nephroliths.

Endoscopic laser technologies in the management of urolithiasis detected in approximately $30 \%$ of urological surgical patients [1] have gained popularity. However, the decades the technologies were used have revealed the disadvantages, and one of them is the complication of contact laser lithotripsy in a form of an infectious inflammatory process in kidneys due to bacterial dissemination of flora from calculi biofilms [2]. In the study by Margel et al. [3] in $25 \%$ of patients, who underwent percutaneous nephrolitholapaxy, sterile urine was combined with positive stone culture. According to Russian researchers, in $41.3 \%$ of cases, microorganisms are found in calculus in sterile urine [4]. In the study [5] among 303 patients with percutaneous nephrolithotomy, $27.4 \%$ of patients were recorded to have systemic inflammatory response syndrome, and sepsis was diagnosed in $7.6 \%$ of these $27.4 \%$ patients. Yang et al. [6] found that $27.4 \%$ among 164 patients who had undergone percutaneous nephrolithotripsy had systemic inflammatory response syndrome postoperatively, and $12.2 \%$ of patients had fever. Intraoperative calculus destruction can trigger the growth activation of microorganisms integrated in a biofilm.

The foregoing motivated the search for novel approaches and techniques of renal calculi fragmentation aimed at solving the problem of postoperative infectious inflammatory processes. One of the prevention options can be the use of new mechanisms and modes of laser

For contacts: Olga S. Streltsova, e-mail: strelzova_uro@ mail.ru 
breakdown providing controlled fragmentation of calculi avoiding microbial dissemination in pelvicalyceal system and restricting the spread of microflora from biofilms.

The essential fault of known techniques of laserinduced lithotripsy of urinary stones is also the restrictions (particular operating modes) imposed on a laser type used, the design of which is frequently costly and difficult to produce. In recent years, to enhance the efficiency of cutting biotissues and teeth, there have been suggested various converters for an operating end of a laser fiber in order to change modes of exposure to tissue [7-9]. Optic fiber exhibits mechanical flexibility, its quartz core being very strong as it can stand high temperature resulted from contact interaction with a calculus. A strongly absorbing coating (SAC) at an optic fiber tip enables to maintain high temperature in the calculus contact area [10].

The aim of the study was to evaluate the developed technique of contact lithotripsy using a strongly heated distal tip of a fiber providing controlled fragmentation of urinary stones.

Materials and Methods. Postoperative kidney stones from 6 to $21 \mathrm{~mm}$ with different X-ray density $(\mathrm{n}=32)$ were used as research objects. We used whole calculi after nephrolithoextraction, pyelolithotomy, nephrectomy, cystolithoextraction. X-ray density of calculi was determined after their removal using computed

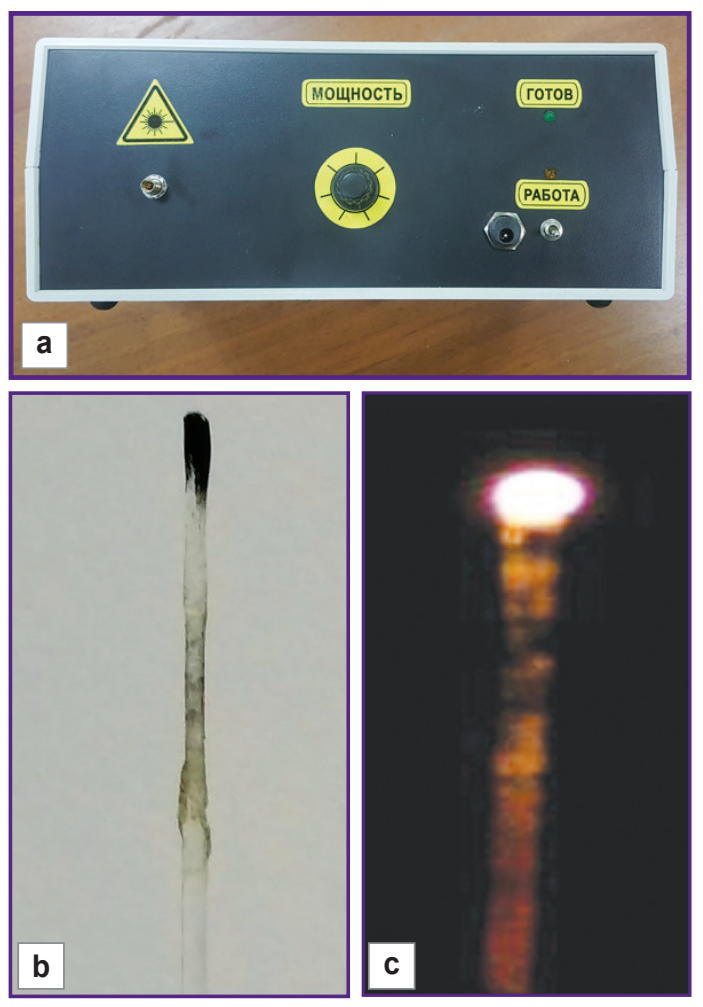

Figure 1. Optothermal fibre converters (Institute of Applied Physics, Russian Academy of Sciences, Russia):

(a) appearance; (b) light guide with SAC on its distal tip; (c) lateral section of a fibre is due to light scatter from a heated tip tomography, and expressed in Hounsfield units (HU). Moreover, we used HD (Hounsfield density) parameter, which was calculated as the ratio of $\mathrm{HU}$ to the maximum crosswise size of a calculus, since X-ray density of calculi - HU - is known to depend on a calculus size [11], and HD enables to neutralize the relationship [12, 13]. Laser fragmentation was performed ex vivo in $0.9 \%$ saline solution, and liquid-free, by a direct contact with a calculus.

For stone fragmentation we applied a standard diode laser $0.97 \mu \mathrm{m}$ (Russia) (Figure 1 (a)) with a continuous wave laser regime, with laser power $15 \mathrm{~W}$. A tip of a silica fiber cleared from the cladding layer was used for stones destruction. As a SAC, we used a solution of graphite carbon microparticles in silicone varnish. SAC was localized at the distal end of the light guide of multimode quartz fiber, diameter core $550 \mu \mathrm{m}$. To obtain a highly absorbing covering, a distal light guide end was sunk in the solution and dried for several seconds at low power (about $1 \mathrm{~W}$ ) (Figure 1 (b), (c)). For fragmentation, calculi were put in a saline solution. The contact zone of the light guide with a stone (heated to $2000^{\circ} \mathrm{K}$ ) [8] was smeared with a $\mathrm{CO}_{2}$ gas stream. The fiber tip resided and moved in the same vertical plane perpendicular to the stone surface.

Results. We demonstrate the first experiments on controlled destruction of stones ex vivo in physiological
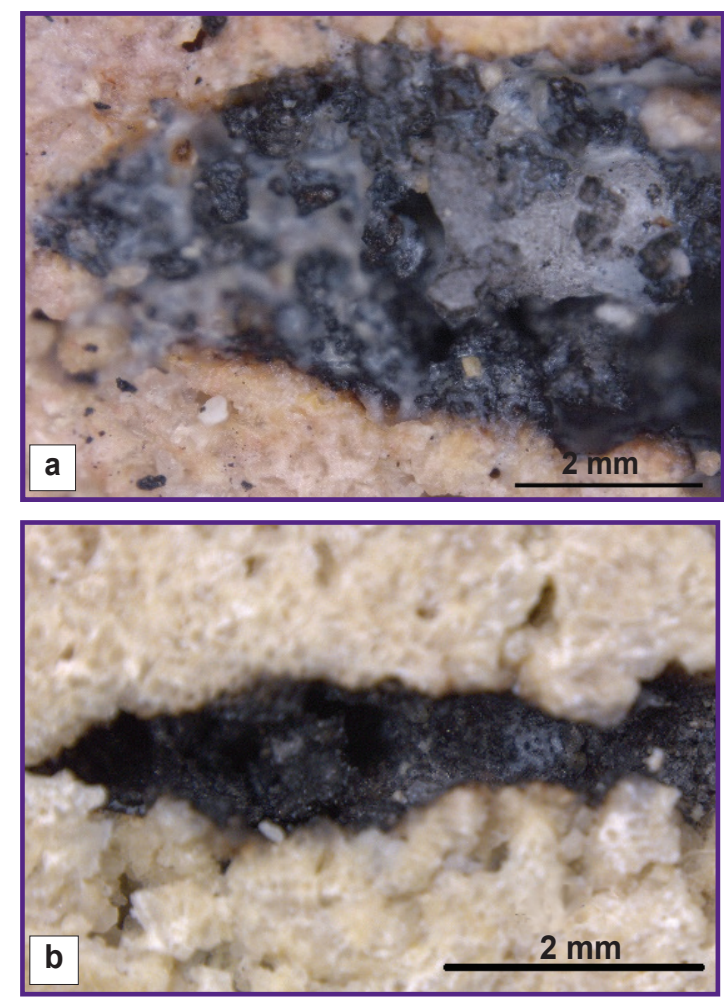

Figure 2. Photo: cross-sectional view of phosphate calculus when exposed to a heated optic fibre, $\mathbf{5 5 0} \mu \mathrm{m}$ in diameter:

(a) dry calculus in atmospheric air is under exposure; (b) a calculus in liquid medium (normal saline) is under exposure 
Examples of calculi fragmentation results using a suggested technique

\begin{tabular}{|c|c|c|c|c|c|}
\hline \multirow{2}{*}{$\begin{array}{l}\text { Chemical type } \\
\text { of calculus }\end{array}$} & \multirow{2}{*}{$\begin{array}{c}\text { Maximal } \\
\text { size before } \\
\text { fragmentation } \\
(\mathrm{mm})\end{array}$} & \multicolumn{2}{|c|}{ X-ray density } & \multirow{2}{*}{$\begin{array}{l}\text { Section } \\
\text { time (s) }\end{array}$} & \multirow{2}{*}{$\begin{array}{l}\text { Calculus } \\
\text { photo }\end{array}$} \\
\hline & & HU & $\mathrm{HD}(\mathrm{HU} / \mathrm{mm})$ & & \\
\hline $\begin{array}{l}\text { Magnesium, } \\
\text { phosphate* }^{*}\end{array}$ & 10 & 158 & 15.80 & 24 (in liquid) & \\
\hline $\begin{array}{l}\text { Magnesium, } \\
\text { phosphate }\end{array}$ & 16 & 355 & 22.19 & 13 (in liquid) & \\
\hline $\begin{array}{l}\text { Magnesium, } \\
\text { phosphate }\end{array}$ & 9 & 343 & 38.11 & 10 (in liquid) & \\
\hline $\begin{array}{l}\text { Phosphate, } \\
\text { calcium, } \\
\text { magnesium, } \\
\text { oxalate } \\
\text { (in atmosphere) }\end{array}$ & 21 & 1,587 & 75.57 & 60 (in air) & \\
\hline $\begin{array}{l}\text { Magnesium, } \\
\text { calcium, oxalates } \\
\text { (in atmosphere) }\end{array}$ & 14 & 1,424 & 101.7 & 25 (in air) & \\
\hline $\begin{array}{l}\text { Magnesium, } \\
\text { calcium, phosphate }\end{array}$ & 10 & 1,060 & 106.00 & 60 (in liquid) & \\
\hline $\begin{array}{l}\text { Magnesium, } \\
\text { calcium, oxalates* }\end{array}$ & 20 & 1,070 & 53.50 & 80 (in liquid) & \\
\hline Oxalates, calcium & 9 & 1,000 & 111.11 & 30 (in liquid) & \\
\hline Phosphate & 17 & 209 & 12.29 & 10 (in liquid) & \\
\hline Magnesium, urates & 6 & 342 & 57.00 & 12 (in liquid) & \\
\hline
\end{tabular}

*Arrow indicates the beginning of fragmentation. 
saline. The results of fragmentation of 32 stones after nephrolithoextraction are presented: transverse size $\sim 10-12 \mathrm{~mm}$. Stones of $5 \mathrm{~mm}$ are easily removed through the endoscope.

Large calculus fragmentation was achieved by using a carbonization mode with mechanical destruction of the surface by high temperature of the optical fiber end (Figure 2). The figure shows the area of destruction of stone in water about $1 \mathrm{~mm}$.

The presence of liquid medium provides the locality of temperature exposure, reducing the area of thermal damage by several times, which is of great importance when operating in the renal cavity system. Carbonization area was found to be significantly smaller if calculi under exposure were in liquid than those dried in atmospheric air: diameters of carbonized canals can differ by over 8 times (see the Table).

The calculus fragmentation time depended on calculus density, cross-sectional size, and was $10-80 \mathrm{~s}$. The maximum cross-sectional size of calculi under study was 4-21 mm. X-ray density of calculi under fragmentation was $158-1,587 \mathrm{HU}$, and $\mathrm{HD}$ value was from 12.29 to $356.00 \mathrm{HU} / \mathrm{mm}$, respectively.

Discussion. In traditional laser lithotripsy, holmium lasers are used, the radiation of which is well absorbed by water in the stones. The stones are irradiated, the water heats up, transforms into vapor, and the pressure of the water vapor breaks the stone into pieces. However, in the stones there are many pathogenic microbes, scattering fragments infect tissues and inflammation is formed.

The technique of controlled cutting of stones into large pieces is required for medical application [14]. Intraoperative destruction of potentially infectious calculus can trigger the activation of growth and dissemination of microorganisms.

In our Urology Clinic, alongside with holmium laser we use contact pneumatic lithotripsy, which also leads to mechanical cracking of a calculus to different-calibre fragments. The presence of postoperative complications in a form of systemic inflammatory response syndrome in patients inspired us to search for other nephrolith fragmentation techniques.

The used mechanism of "hot spot" enabled to avoid calculi destruction with small flakes scattered by irrigation fluid current in the renal cavity system and provide a controlled break along the marked line. The novel aspect in the developed technique of contact lithotripsy is that a distal tip of the optic fiber is applied by a highly absorbing layer that results in calculus fragmentation due to high temperature localized at the optic fiber tip, i.e. there is calculus burning.

Calculi with X-ray density of over $1,400 \mathrm{HU}$ are hardly fragmented in water, however, in atmospheric air their fragmentation proceeds successfully. On the other hand, potentially infected struvite campuses, apatites, ammonium urates, and others [15] appeared to have an X-ray density at 1,400 $\mathrm{HU}[16,17]$, which is sufficient for their fragmentation by the technique used. Less than $15 \mathrm{~s}$ (see the Table) are necessary for the fragmentation of stones with a porous structure containing much microflora.

The suggested technique enables to control the fragmentation of potentially infected calculi in the renal cavity up to the fragments, which can be afterwards taken out mechanically through a nephroscope, or Amplatz tube during percutaneous nephrolithotripsy. It enables to provide minimal microbial dissemination of renal tissue during endoscopy by the content of biofilms associated with calculi. It is expected that under high temperature at the point of light guide contact with a calculus there is no yield of bacterial flora from biofilms contained in a calculus.

Conclusion. We demonstrate the first experiments on controlled laser destruction of stones with the use of carbon-containing optothermal fibre converters. The use of a highly absorbing covering of the laser end enables to provide the break of a stone in lithotripsy along the marked line, and avoid small fragmentation. Therefore it prevents intraoperative microbial dissemination of renal tissue from biofilms of potentially infected calculi.

Study Funding. The study was supported by Russian Science Foundation grant \#14-15-00840 П.

Conflicts of Interest. The authors have neither potential nor existing conflicts of interest related to the present study.

\section{References}

1. Antonov A.V. Minimally invasive treatments for kidney stones disease. Urologicheskie vedomosti 2013; 3(1): 33-38.

2. Didenko L.V., Tolordava E.R., Perpanova T.S., Shevlyagina N.V., Borovaya T.G., Romanova Yu.M., Cazzaniga M., Curia R., Milani M., Savoia C., Tatti F. Electron microscopy investigation of urine stones suggests how to prevent post-operation septic complications in nephrolithiasis. J Appl Med Sci 2014; 3(4): 19-34.

3. Margel D., Ehrlich Y., Brown N., Lask D., Livne P.M., Lifshitz D.A. Clinical implication of routine stone culture in percutaneous nephrolithotomy - a prospective study. Urology 2006; 67(1): 26-29, https://doi.org/10.1016/j. urology.2005.08.008.

4. Palagin I.S., Sukhorukova M.V., Dekhnich A.V., Edelstein M.V., Shevelev A.N., Grinyov A.V., Perepanova T.S., Kozlov R.S. Current state of antibiotic resistance of pathogens causing community-acquired urinary tract infections in Russia: "DARMIS" study (2010-2011). Klinicheskaya mikrobiologiya $i$ antimikrobnaya khimioterapiya 2012; 14(4): 280-302.

5. Koras O., Bozkurt I.H., Yonguc T., Degirmenci T., Arslan B., Gunlusoy B., Aydogdu O., Minareci S. Risk factors for postoperative infectious complications following percutaneous nephrolithotomy: a prospective clinical study. Urolithiasis 2015; 43(1): 55-60, https://doi.org/10.1007/ s00240-014-0730-8.

6. Yang T., Liu S., Hu J., Wang L., Jiang H. The evaluation of risk factors for postoperative infectious complications after percutaneous nephrolithotomy. Biomed Res Int 2017; 2017 : 4832051, https://doi.org/10.1155/2017/4832051. 
7. Malskat W.S., Poluektova A.A., van der Geld C.W., Neumann H.A., Weiss R.A., Bruijninckx C.M., van Gemert M.J. Endovenous laser ablation (EVLA): a review of mechanisms, modeling outcomes, and issues for debate. Lasers Med Sci 2013; 29(2): 393-403, https://doi.org/10.1007/s10103-0131480-5.

8. Bredikhin V., Kamensky V., Sapogova N., Elagin V., Shakhova M., Snopova L., Bityurin N. Indirect laser surgery. Applied Physics A 2016; 122(3): 181, https://doi.org/10.1007/ s00339-016-9734-2.

9. Belikov A.V., Skrypnik A.V., Kurnyshev V.Y., Shatilova K.V. Experimental and theoretical study of the heating dynamics of carbon-containing optothermal fibre converters for laser surgery. Quantum Electronics 2016; 46(6): 534-542, https://doi.org/10.1070/qel16134.

10. Bredikhin V.I., Bityurin N.M., Kamenskiy V.A., Smirnova L.A., Salomatina E.V., Strel'tsova O.S., Pochtin D.P. Method of contact lithotripsy. Patent RU 2604800. 2015.

11. Demiray Ö., Cüce F., Çevik E., Çataloğlu B., Kalemci S. Could spot urine analysis of calcium and uric acid help predict density of urinary stone in computerized tomography? A preliminary study. Minerva Urol Nefrol 2016; 68(4): 342-347.
12. Motley G., Dalrymple N., Keesling C., Fischer J., Harmon W. Hounsfield unit density in the determination of urinary stone composition. Urology 2001; 58(2): 170-173, https://doi.org/10.1016/s0090-4295(01)01115-3.

13. Shahnani P.S., Karami M., Astane B., Janghorbani M. The comparative survey of Hounsfield units of stone composition in urolithiasis patients. J Res Med Sci 2014; 19(7): 650-653.

14. Teichman J.M., Vassar G.J., Bishoff J.T., Bellman G.C. Holmium: YAG lithotripsy yields smaller fragments than lithoclast, pulsed dye laser or electrohydraulic lithotripsy. J Urol 1998; 159(1): 17-23, https://doi.org/10.1016/S00225347(01)63998-3.

15. Türk C., Knoll T., Petrik A., Sarica K., Straub M., Seitz C. Guidelines on urolithiasis. European Association of Urology; 2011.

16. Kuwahara M., Kageyama S., Kurosu S., Orikasa S. Computed tomography and composition of renal calculi. Urol Res 1984; 12(2): 111-113, https://doi.org/10.1007/bf00257175.

17. Li X.-H., Zhao R., Liu B., Yu Y.-Q. Determination of urinary stone composition using dual-energy spectral CT: initial in vitro analysis. Clin Radiol 2013; 68(7): e370-e377, https:// doi.org/10.1016/j.crad.2012.11.022. 